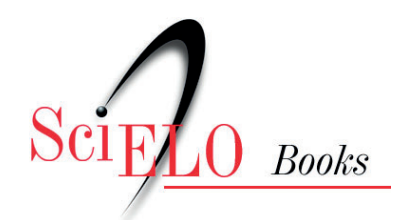

\title{
6. De memória em memória trançando histórias na educação de jovens e adultos
}

\author{
Jane Paiva
}

PAIVA, J., comp. De memória em memória: trançando histórias na educação de jovens e adultos. In: Aprendizados ao longo da vida: sujeitos, políticas e processos educativos [online]. Rio de Janeiro: EDUERJ, 2019, pp. 113-149. Pesquisa em educação/Educação ao longo da vida series. ISBN: 978-65990364-9-1. https://doi.org/10.7476/9786599036491.0007.

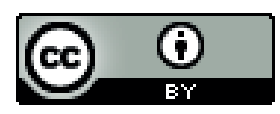

All the contents of this work, except where otherwise noted, is licensed under a Creative Commons Attribution 4.0 International license.

Todo o conteúdo deste trabalho, exceto quando houver ressalva, é publicado sob a licença Creative Commons Atribição $\underline{4.0}$.

Todo el contenido de esta obra, excepto donde se indique lo contrario, está bajo licencia de la licencia Creative Commons Reconocimento 4.0. 


\section{6}

\section{De memória em memória: trançando histórias na educação de jovens e adultos}

Jane Paiva

\section{Introdução}

O artigo apresenta a pesquisa realizada com apoio do programa Prociência, da Universidade do Estado do Rio de Janeiro (UERJ), e com recursos de bolsa de pesquisa do Edital Jovem Cientista (2015-2017) da Faperj, que possibilitou condiçôes de desenvolvimento e envolvimento de equipe de pesquisadores vinculada ao Grupo de Pesquisa CNPq Aprendizados ao longo da vida: sujeitos, politicas e processos educativos, no Programa de Pós-Graduação em Educação (ProPEd), da Faculdade de Educação da UERJ.

Algumas questóes serviram para orientar o trabalho em um contexto integral, animadas pela curiosidade que subjaz ao interesse temático na definição de um objeto de pesquisa: a) que concepção(óes) de alfabetizaçáo de adultos subjazem a documentos, programas, materiais didáticos elaborados pelas duas instituiçôes estudadas vis-à-vis a materiais a eles contemporâneos de acervos latino-americanos? b) Como essa(s) concepção(óes) se vinculam a enunciaçóes internacionais de acordos 
no campo e a liçóes da educação popular que as precedeu? c) Que conteúdo político a alfabetização e programas a ela correlatos contêm? Que vinculação esses conteúdos expressam com o regime vigente no período e em relação à realidade latino-americana? d) Que contribuiçóes o resgate dos sentidos da alfabetização no período de 1970 a 1990 na América Latina oferece à compreensão da história da EJA e de sua continuidade?

Para respondê-las, enunciou-se como objetivo geral compreender e interpretar complexamente sentidos e concepçóes de alfabetização em contexto, expressos em programas e projetos de alfabetização de adultos, de 1970 a 1990, especificamente desenvolvidos como políticas públicas pelas Fundaçóes Mobral e Educar, em interlocução com produçóes regionais latino-americanas e internacionais. Valendo-se da memória material contida em acervos documentais e materiais didáticos, assim como da memória oral de protagonistas do campo pedagógico dessas instituiçóes, visava (re)ver e formular um conhecimento sobre alfabetização de adultos desse período da história do Brasil. Para tal intento, mapeou documentos, coleçóes e acervos de alfabetização de adultos das Fundaçóes Mobral e Educar existentes no Centro de Referência e Memória da Educação Popular e EJA (CReMEJA), buscando produzir um mapa conceitual dos sentidos prevalentes no período estudado, chegando à atualidade. Levantou documentação de conferências e acordos regionais latino-americanos e internacionais do período, interpretando concepçôes de alfabetização, e verificando/interpretando vínculos com os acervos estudados. Estabeleceu vinculaçóes entre o período em estudo e realidades de América Latina, levantando e mapeando materiais e acervos no Centro de Investigaciones y Estudios del Instituto Politécnico Nacional (Cinvestav, no México, D.C.) e no Centro de Cooperación Regional para la Educación de Adultos en América Latina y el Caribe (CREFAL) e, junto a estudiosos do 
campo, cujas referências balizam compreensóes e concepçóes de alfabetização, como Judith Kalman (Cinvestav/Departamento de Investigaciones Educativas/DIE); mapeou e categorizou a participação de técnicos especialistas que atuaram nas instituiçóes investigadas, diretamente envolvidos com o campo pedagógico e com programas de alfabetização. Entrevistou, após seleção criteriosa, dois técnicos afeitos à temática, resgatando memórias sobre experiências de formulaçáo, implantaçáo, acompanhamento e avaliação de programas de alfabetização e de outros deles decorrentes (como de formação continuada de alfabetizadores, por exemplo); e em interlocução com projetos de cooperação internacional em desenvolvimento, envolveu a formação de pesquisadores - graduandos de IC, mestrandos, doutorandos e pós-doutorandos, além de professores da educação básica. Compôs, por último, epistemologicamente, o cenário político pedagógico em que se deu a alfabetização de adultos no período, revelando fontes, disponibilizando-as à consulta pública e disseminando a produção.

Três grandes etapas foram previstas para os três anos de desenvolvimento. Circunstâncias políticas vividas na Universidade, com greve prolongada e restrição da infraestrutura, em muito interferiram no cumprimento pleno do previsto. Sendo a pesquisa documental, em maioria, em fontes relacionadas a programas de alfabetização de adultos e outros correlatos, o cuidado com a preservação da memória recolhida exigia resguardar um patrimônio do povo brasileiro. Assim, associou-se ao projeto do Centro, que também integrou a pesquisa em curso, um novo projeto de extensão da professora da Faculdade de Educação, Fátima Lobato Fernandes, pertencente ao GP, cuja finalidade tratou de disponibilizar, on-line, em banco de dados como acervo virtual, a documentação que preserva a memória da EJA. Um segundo professor, Guilherme Vargues, foi responsável pela escolha e orientação quanto ao uso do banco de dados (Wordpress) que suporta a 
página e o acervo que continua, diariamente, sendo atualizado. A concepçáo do projeto de pesquisa, dessa forma, potencializava o âmbito da ação e o papel da universidade pública na consolidação das relações com a sociedade. A disponibilização ampla de acervos de forma virtual permitiria o acesso a pesquisadores e interessados, tornando pública a memória que sustenta um pouco da história da educação de jovens e adultos no país.

Com esses dados iniciais de destaque, apresentam-se as etapas executadas, assim resumidas:

a) coleta seletiva de documentos, de literatura especializada, realização de intercâmbios nacionais e internacionais para o tema da alfabetização de adultos, explorando fontes documentais e orais, a serem interpretadas à luz de estudos nacionais e internacionais no campo da alfabetização, com vista a reconstruir um tempo histórico da educação de adultos, ocorrido nas décadas de 1970-90, nas instituiçóes Mobral e Educar. A escolha dessas instituiçóes teve o sentido de trazer à luz do conhecimento o que se conseguiu recuperar das produções realizadas, considerando que a extinção da Fundação Educar (sucedânea do Mobral) desprezou acervos e a memória material documentos, livros e materiais didáticos e audiovisuais e a biblioteca - rigorosamente acumulados durante duas décadas. No Brasil, a coleta de material bibliográfico foi feita em artigos de revistas qualificadas com a temática da alfabetização, publicados em periódicos nacionais e latino-americanos, não apenas entre 1970 e 1990. Textos trabalhados, principalmente, na forma de fichas-resumo e, posteriormente, em mapas conceituais (Tavares, 2007; Souza e Boruchovitch, 2010; Moreira, 2012); 
b) tratamento inicial de dados coletados, de levantamento de protagonistas e seleção e oitiva de memorialistas. $\mathrm{O}$ tratamento de dados se fez segundo categorias de compreensão de concepção(óes) de alfabetização que emergiram de diferentes movimentos realizados pela revisão de literatura; do intercâmbio com estudiosos do campo; e dos próprios documentos selecionados, compondo mapas conceituais. O levantamento de protagonistas se fez entre alguns que atuaram nas instituiçôes referidas, como depoentes, privilegiando-se os que atuaram em programas de alfabetização e/ou outros a eles vinculados (como o de formação de alfabetizadores, além de programas de saúde, culturais etc.), contribuindo como possíveis memorialistas, narrando suas memórias e contribuindo com a investigação;

c) compreensão de dados das entrevistas face a face aos dados documentais, elaboração de relatório e disponibilização digital dos materiais da pesquisa, respondendo questóes que não apenas se circunscreviam ao âmbito epistemológico e pedagógico sobre alfabetização de adultos, mas que também exigiam a interpretação do contexto. Por isso, a compreensão dos dados tomou por base o ciclo de políticas (Frey, 2000 e Bowe et al, 1992), e elementos históricos evocados pelos memorialistas, cumprindo o que Frey (2000, p. 226) entende como uma sequência de fatos/ eventos do processo político que podem ser investigados no que diz respeito às constelaçóes de poder, às redes políticas e sociais, e às práticas pedagógicas do período em referência. Dessa forma, entendeu-se que o esforço de sistematização do conhecimento resgatado se inclinava a produzir uma história da alfabetização de adultos do período estudado que, ao ser interpretada, trazia à luz aspectos até então mantidos à sombra em relação às instituiçóes 
investigadas, principalmente pelas negaçóes ideológicas que cercaram sua atuação, sem ultrapassar a camada superficial de sentidos e concepçóes com os quais atuaram, repleta de contradiçóes inexoráveis dessa atuação. A disponibilização dos materiais utilizou recursos digitais, oferecendo-se no momento presente ao público por uma página web (www. cremeja.org), com banco de dados para consulta de acervos e de produçóes acadêmico-científicas sobre alfabetização de adultos e sobre educação de adultos.

\section{Método e metodologia: estudo e planejamento das açóes da pesquisa}

O método de pensamento pela perspectiva da complexidade e pela noção de redes de conhecimentos aproximou enunciaçóes e compreensóes, atravessadas por diversos campos (trans)disciplinares, para pensar a realidade. Para tanto, teceu-se um modo de apreender náo apenas expressóes conceituais de programas e projetos, mas as teias transdisciplinares que se formam entre eles, relacionadas às diversas dimensôes da vida sociopolítica e cultural em que se deram/foram possíveis.

Entendendo que essas concepçóes só poderiam ser capturadas pensando-se pela perspectiva da complexidade, lançou-se mão de leituras acadêmicas que auxiliaram a produção de um juízo crítico e colaboraram na formulação das questóes tanto da pesquisa quanto das entrevistas, enlaçando métodos de pensamento e metodologias. Essas leituras tiveram papel também na construção dos instrumentos e no desenvolvimento de técnicas adotadas na investigação, assim como nas observações e na tradução do material produzido no campo.

A sistemática busca e organização da memória contida em acervos e em narrativas que evocam a memória de depoentes foi o caminho percorrido para reconstruir parte das concepçóes 
de educação popular, de EJA e de alfabetização do período de tempo em estudo - 1970-90. Para isso, considerou-se que concepçóes, por sua natureza histórica, têm temporalidade e espacialidade, e são multidimensionais, apesar de serem sensíveis aos movimentos dos sujeitos em açóes de fazer e desfazer, pensar e transformar o mundo. Assim, por meio da interpretaçáo de documentos e das narrativas dos sujeitos que vivenciaram um lugar estratégico dentro das instituições - Mobral e Fundação Educar —, buscou-se conhecer os modelos praticados junto a adultos que frequentaram cursos de alfabetização, para suprir a "deficiência" histórica provocada pela ausência do poder público, sobretudo em áreas rurais, em cumprimento de ordenanças políticas.

A história oral foi a abordagem adotada para responder algumas perguntas da pesquisa, dialogando com textos de alguns autores em destaque, como Paul Thompson (1992) e Verena Alberti (2005). Além desses autores, textos referentes ao conceito de entrevista compreensiva do sociólogo francês Jean-Claude Kauffman (2013). Adotamos uma proposta semelhante à denominada Methodology of making sense as research, ${ }^{1}$ como proposto pelas pesquisadoras canadenses Kathleen Nolan e Jennifer Tupper (2013), própria para trabalhos coletivos de pesquisa, que busca conhecer conceitos postulados pelas teorias selecionadas e suas relaçóes práticas. Assim, o trabalho hermenêutico se fez na troca dos sentidos apreendidos pelos participantes, com base nos textos lidos e em diálogo com as experiências obtidas em práticas de entrevistas em pesquisas já realizadas.

\footnotetext{
1. "Making sense as research methodology necessitated relational reading, reflecting, and researching both within and beyond the scope of our 'field' trips [...]. Making sense as research methodology involves the co-construction of meaning, not through the emergency of data but the reading of theory" (Nolan e Tupper, 2013, p. 11).
} 
Um vídeo envolvendo práticas de entrevistas individuais e coletivas serviu para a preparação dos integrantes do GP: atribuíram-se sentidos às imagens do Fora de Série, que envolviam jovens da EJA. O vídeo motivou discussóes entre os componentes, náo só estimuladas pelos depoimentos registrados, como pela narrativa do making of da experiência de entrevista. A temática do diálogo em rede caminhou para assuntos relacionados a técnicas relevantes a serem observadas no planejamento prévio das entrevistas; os cuidados técnicos durante a gravação e a exposição do depoente; o tratamento do material produzido etc. Esse movimento permitiu muitas aproximaçóes práticas dos conceitos e dicas de preparo de entrevistas em pesquisas de história oral.

Alertados pelo que os autores argumentavam sobre procedimentos da entrevista, e com a intençáo de explorar ao máximo o que poderia ser encontrado em campo, organizaram-se simulaçóes de entrevistas em que alguns participantes foram entrevistadores e, outros, os entrevistados. Uma câmera doméstica de gravação de vídeo e um gravador de voz foram utilizados, depois que - sem que as pessoas a serem entrevistadas se fizessem presentes - os participantes definissem em dois subgrupos a temática e as questôes que orientariam a entrevista, assim como o entrevistador, experimentando uma situaçáo real de entrevista pela abordagem da história oral. Em encontros posteriores, os presentes puderam ver e discutir o resultado audiovisual e avaliar formas de se construir o ambiente da entrevista; a disposiçáo local de assento dos participantes; a posição dos objetos de captura de imagem e do som; os tipos de tomada e planos de gravaçáo; perceber os fatores que contribuíram e os que atrapalharam a dinâmica dos diálogos e a qualidade das gravaçóes, o que dificultaria o possível

2. O vídeo é produção da pesquisa Jovens fora de série do Observatório Jovem da UFF, coordenado por Paulo Carrano e produzido por Ana Karina Brenner, que integra nosso GP. 
trabalho de transcrição e tratamento do material etc., a fim de garantir a qualidade do que fora realizado.

Depois da experiência, a organização do roteiro de questóes teve lugar, visando a auxiliar o processo de fazer emergir da memória de depoentes os aspectos perseguidos para responder as questóes da pesquisa. A intençáo era, como Thompson (1992, p. 261) recomenda, "[...] ir além das generalizaçóes estereotipadas ou evasivas e chegar a lembranças detalhadas" que permitissem definir as concepçóes de alfabetização que orientaram as propostas das instituiçóes em análise. $\mathrm{O}$ roteiro seguia a recomendação de Jacques Ouzouf (apud Becker, 2006) para acessar o que denominou de "arquivos provocados", 3 deixando abertura para o inusitado, comum de ocorrer quando a memória provocada e liberada detona outras memórias latentes.

Benjamin (2012, p. 271), para falar da profundidade e da riqueza do pensamento quando este se coloca disponível ao inusitado, faz uso da alegoria do tapete:

[...] Em todo conhecimento, disse ele, deve conter um mínimo de contrassenso, como os antigos modelos de tapete ou de frisos ornamentais, onde sempre se pode descobrir, nalgum ponto, um desvio insignificante de seu curso regular. Em outras palavras: o decisivo não é a progressáo de conhecimento em conhecimento, mas o salto em cada conhecimento isolado em si. É a marca imperceptível da autenticidade que os distingue de todos os objetos em série fabricados segundo um padráo.

Ao pensar nos instrumentos capazes de provocar esses arquivos da memória, e que fizessem emergir fatos inusitados, contudo

3. "Aliás, podemos dizer que os arquivos provocados pertencem à mesma categoria das recordaçôes ou memórias, ainda que estas possam ser autoprovocadas, considerando que alguns escreveram suas memórias sem que isso lhes fosse realmente pedido!” (Becker, 2006, p. 28) 
reveladores de realidades escondidas aos olhos do pesquisador, buscávamos poder revelar o fio que escapava à linearidade do trançado até então produzido pelo conhecimento oficial: as memórias que viriam à tona pelas narrativas do sujeito e que, portanto, careciam de um olhar mais apurado e detido. Essa compreensão nos obrigou a construir uma nova configuraçáo do diálogo possível, aquele que refaz no ato da entrevista o roteiro prévio, imposto pela necessidade de reelaborar questóes para conhecer melhor o que se apresenta como um novo fio a seguir na trama. Esse desvio, pois, poderia ser a promessa de um conhecimento que, problematizado, traria maior fecundidade para o esforço de aproximação à realidade que se queria compreender, e de reforço à singularidade das concepçóes de alfabetização adotadas pelas instituiçóes em pesquisa ou pelas concepçóes que os depoentes - ocupantes de lugares importantes nos projetos condutores das ações práticas desses órgãos — tomaram para si.

No trabalho com as fontes orais, apoiamo-nos na concepção de memória como reconstrução (Lang, 1996, p. 35) - evocação “[...] de um passado visto pela perspectiva do presente e marcado pelo social, presente a questão da memória individual e da memória coletiva". Mesmo optando pelo tipo de entrevista que Alberti (2005) classifica de entrevista temática, cujo tema está ligado à trajetória de vida do sujeito, entendemos que essa prática não se distanciava do método biográfico comum à história oral. Debruçávamo-nos sobre o indivíduo e os cortes temáticos realizados em sua trajetória a partir do(s) lugar(es) ocupado(s) na(s) instituição(óes) a que esteve ligado, o que mantinha a entrevista, de certa forma, relacionada com a vivência, a experiência e com concepçóes constituídas no/pelo indivíduo (Alberti, 2005, pp. 37-8).

Planejamos as técnicas, os instrumentos e os métodos para o desenvolvimento das entrevistas, entendendo-as como "encontros dialógicos" e toda atenção, cuidado e respeito às falas dos 
sujeitos depoentes eram exigidos, porque nelas residiam novos conhecimentos que poderiam emergir ou não, segundo a dinâmica do encontro promovido. $\mathrm{O}$ roteiro com questóes prévias deveria induzir o diálogo, que prosseguiria como uma conversa quase informal, deixando o entrevistado à vontade na construçáo de seus discursos e consideraçóes, permitindo o fluir das memórias e criando abertura para a emersão de informaçóes que seriam impossíveis ou improváveis de prever antes do momento da entrevista. Cabia a nós, pesquisadores, decidir sobre as melhores formas de abordagem e criar um ambiente favorável a essa fruição, segundo o conceito de entrevista compreensiva. ${ }^{4}$

A seleção dos protagonistas aconteceu de acordo com o tipo de envolvimento com a temática em estudo, considerando o desejo de cada convidado em narrar suas memórias; sua inserção na temática e sua efetiva participação na instituição e as possíveis contribuições à investigação. Para a realização das entrevistas, foram feitos contatos prévios. Definimos que não mais de três pessoas do GP participariam das entrevistas, para não inibir o depoente: uma que operaria a câmera; ${ }^{5}$ uma entrevistadora (a coordenadora da pesquisa); uma em apoio técnico (verificar os gravadores etc.) e em registros escritos (que apoiaria a entrevistadora com alguma ideia que escapasse e devesse ser aprofundada).

4. Conceito desenvolvido por Jean-Claude Kaufmann (2013), que critica o academicismo por entender que o modelo teórico náo deve ser uma "camisa de força", aprisionando o pesquisador a conceitos engessados que encaixotam o objeto, que acabam conduzindo o pesquisador a comprovaçóes e não a descobertas ou criaçóes. Para o autor, a entrevista como instrumento de pesquisa deve ser pautada na flexibilidade, embora não descarte o preparo técnico do pesquisador para o ato da entrevista em si. Contudo, o ato de entrevista deve transcorrer como uma conversa entre duas pessoas dispostas a dividir seus conhecimentos e suas ideias. Nessa relação o entrevistado é ouvido com atençâo e respeito, pois detém um conhecimento que, a princípio, o entrevistador não possui, mas quer descobrir (Ferreira, 2014).

5. A indicação das operadoras de câmera foi, propositalmente, feita para as bolsistas de IC, pela oportunidade de vivenciar o processo no ato de sua realização, o que além de significar um momento de experiência e aprendizagem, favoreceria o trabalho posterior de decupagem e transcrição a ser feito. 
Ao final dos contatos realizados, pôde-se contar com a participação de duas depoentes: uma que exerceu função gestora do setor pedagógico da instituição Mobral nacional por cerca de cinco anos e outra que iniciou suas atividades em coordenação estadual do Piauí, vindo depois para o órgão central.

\section{Alfabetização: concepçóes e compreensóes}

Para Cook-Gumperz (2008, p. 31) qualquer concepção de alfabetização é inseparável das circunstâncias específicas do contexto histórico. Ao balizar dois autores com diferentes pontos de vista sociogeográficos - Raymond Williams (1961) e Akinnaso $(1982,1992)$-, obtém dois enfoques contrastantes sobre os efeitos da alfabetização no pensamento social: o primeiro enxergando “[...] uma progressão histórica, na qual a alfabetização por meio da escolarização compulsória leva à tomada de poder político e possibilidade de mudança social"; o segundo, "[...] refletindo sobre o resultado de se permitir que a alfabetização pela escolarização em estilo ocidental domine como único caminho para a mudança social e econômica”, resultando na desvalorização das tradiçóes não-ocidentais.

Os últimos séculos da experiência ocidental forjaram um "vínculo inevitável" entre taxas de alfabetização e desenvolvimento socioeconômico de uma sociedade, contudo, muitas vezes são traçadas comparaçóes entre efeitos e consequências da alfabetização em sociedades essencialmente incomparáveis ${ }^{6}$ (Goody, 1977 apud Cook-Gumperz, 2008, p. 32).

\footnotetext{
6. Esta ideia conflui com o pensamento de que determinada monocultura do saber formal (de Boaventura de Sousa Santos) dificulta que se identifiquem diferentes formas de proceder saberes, temporalidades, culturas, escalas e sistemas de produção - invisibilizando-as, a partir da supremacia e universalizaçáo de valores próprios do capitalismo ocidental.
} 
Antes do desenvolvimento do sistema de educação em massa, o domínio da leitura e da escrita se deu por muito tempo mediante interação informal, em grupos específicos, aprendendo sozinhas com pais, vizinhos, sem licença ou treinamento, em quaisquer espaços.

Só no século XX se consolidou a noção de alfabetização escolar única, padronizada, assim como o paradigma psicométrico, da testagem, e o processo de aprendizagem é visto como evolutivo, universal. Os fracassos em testes passam então a significar falta de capacidade do próprio indivíduo. Nessa lógica, os menos prósperos em realizaçóes educacionais tornam-se os menos merecedores do ponto de vista social. Com a burocratizaçáo crescente da escolarizaçáo por meio de instrumentos técnicos e a ênfase na sofisticaçáo das técnicas de aprendizagem e ensino, acreditava-se alcançar a força de trabalho educada. O objetivo da escolarizaçáo em massa era controlar a alfabetização; não promovê-la - conclui a autora (Cook-Gumperz, 2008, pp. 34; 40).

A cultura letrada popular pluralista - "alfabetizaçóes" —, que não estimulava a separação e a classificação de indivíduos, foi sendo substituída por uma cultura da educação pública em massa (que proporcionou condiçóes organizacionais para separação e classificação por meio de práticas de alfabetização mensuráveis e avaliativas).

Kalman (1996a), ao refletir sobre as perspectivas distintas de autores que se dedicaram à questáo da alfabetização desde os anos 1960, também descreve que nesse período predominaram as técnicas de aprendizado. O êxito do estudante dependia do desempenho pessoal na aquisição da língua escrita ao dominar as letras, assimilar os sons e aplicar os conhecimentos: tais requisitos determinavam a capacidade do indivíduo frente à sociedade. Havia reconhecimento social e histórico da língua escrita, todavia, este se dava a partir do paradigma da neutralidade. Kalman (1996a, 
pp. 40-1) recupera uma das ideias de incapacidade, então vigente, e indica que, em 1964, os organizadores de uma conferência patrocinada pela Agência do Departamento de Estado dos Estados Unidos definiram a alfabetização como "o passo inevitável” para o desenvolvimento de economias nacionais e para a democracia.

$\mathrm{O}$ vínculo da alfabetização com o desenvolvimento das sociedades capitalistas se reforça desde então, e não à toa o Banco Mundial, o Banco Interamericano do Desenvolvimento, o Fundo Monetário Internacional passaram a ditar e a financiar, segundo suas concepçóes e lógicas, programas e projetos em países cuja condição histórica permitia o avanço do capitalismo internacional, pela exploração das riquezas e do trabalho humano, com menor desperdício e a preços vis. Para isso, a educação, desde a alfabetização de adultos, era essencial.

A autora (Kalman, 2003, p. 5) situa o surgimento do interesse por investigar os usuários da leitura e da escrita, seus propósitos, práticas e contextos no final da década de 1970; esforço nutrido fundamentalmente por duas importantes escolas de pensamento e ação: a antropologia (com a premissa de que as formas comunicativas e simbólicas de que nos utilizamos para construir significados não são universais, mas sim práticas localizadas e culturalmente diversificadas e múltiplas) e o pensamento de Paulo Freire (que a partir do conceito de leitura de mundo incitava a compreensão de que textos escritos encontram-se inseridos na vida com fins sociais, econômicos, culturais, ideológicos e políticos).

[...] A diferencia de la visión de los organismos internacionales que promovían la alfabetización como un medio para favorecer la industrialización y la incorporación de la población a la fuerza de trabajo manufacturera, Freire concebía a la alfabetización como una herramienta potencial para los adultos reflexionaren sobre su vida y su lugar en el mundo (Kalman, 1996a, p. 42). 
Kalman (2001), em resenha sobre a coletânea Lecturas para la educación de adultos (organizada por Sylvia Schmelkes), ${ }^{7}$ apresenta continuidades e descontinuidades sobre o tema alfabetização. Para a autora, dada a desigualdade no acesso à educação básica e à cultura escrita, a alfabetizaçáo segue sendo prioridade na educaçáo de adultos, sob qualquer ângulo. Ao revisar documentos oficiais, a autora vislumbra uma conceptualização cada vez mais complexa do binômio analfabetismo/alfabetismo: no início da década de 1980 "presentan a la alfabetización como un mal vencible, eliminable si se cuenta con un plan estratégico correcto"; posteriormente, como pode ser observado no documento Analfabetismo y alfabetización: visión introductoria (1990, OREALC apud Kalman, 2001), desenvolve-se outra abordagem em relação ao analfabetismo:

[...] [o analfabetismo] guarda relación con la concepción tradicional que definía a las poblaciones analfabetas en función de la ausencia de escritura y con la vigencia de las prácticas orales de la región. Esta oralidad no es sólo patrimonio de las culturas indígenas ágrafas, sino también se hace presente en comunidades campesinas urbanas donde se perciben serias dificultades en sus estudiantes para utilizar los códigos escritos.

A autora ainda aponta que esta abordagem passa a ressaltar, com sensibilidade, o aspecto cultural e comunicativo da língua escrita - aspecto até entáo ausente nos planos e propostas oficiais em seu país (México). Em 1994, lembra, a Declaração de Délhi afasta-se da visão alfabetização/pós-alfabetização (que supôe que primeiro é preciso aprender a decifrar o código para depois se

7. A coletânea reúne, em cinco volumes, um grande número de trabalhos, inclusive documentos oficiais, resultados de pesquisas, análises políticas, discussōes pedagógicas e reflexôes sobre o campo da educação de pessoas jovens e adultas. 
ler o texto), propondo conteúdos e métodos mais adequados às necessidades de aprendizagem dos indivíduos e da sociedade no enfrentamento de problemas urgentes. Na Declaração de Hamburgo (CONFINTEA V), em 1997, a alfabetização aparece relacionada a conhecimentos e capacidades básicas necessárias às pessoas em um mundo em rápida evolução; e o acesso à leitura e à escrita declarado um direito fundamental. Nesse mesmo documento, a alfabetização é apontada como um catalisador da participação dos sujeitos em atividades sociais, culturais, políticas e econômicas, assim como ferramenta necessária para garantir a aprendizagem ao longo da vida. Mas, para a autora, muitas abordagens no início dos anos 1990 ainda se preocupavam com a classificação dos “analfabetos".

É recorrente na obra de Freire (apud Ferraro, 2009, p. 7 apud Sguissard, 2011) a rechaça às concepçóes de analfabetismo como enfermidade, "chaga", "erva daninha" a ser erradicada. Freire denunciava o fenômeno do analfabetismo como "uma das expressôes concretas de uma realidade social injusta".

Ferraro (2009 apud Sguissard, 2011), em sua obra História inacabada do analfabetismo no Brasil, cita a construção social do analfabetismo como questáo nacional mostrando, “[...] com base nos debates parlamentares, como os termos analfabetismo e analfabeto foram transformados em verdadeiro estigma, e como o problema do analfabetismo, de questáo pedagógica, se transformou numa questão eminentemente ideológica” já nos idos do Segundo Reinado. Esta construção social relacionou-se intimamente com:

[...] os debates, na Câmara dos Deputados, em torno dos projetos liberais da reforma eleitoral ocorridos nesse período. Visava-se então a aprovação da Lei Saraiva, de 9 de janeiro de 1881, "que incluiu na legislação e na prática política a exclusão dos analfabetos do direito de voto" (Ferraro, 2009, p. 17 apud Sguissard, 2011, p. 247). 
Levando em conta o questionamento da dicotomia estrita entre analfabeto/alfabetizado, Kalman (2005, pp. 13-4) afirma que em muitos países ocidentais economicamente fortes chamam-se "analfabetos" aqueles que não terminaram o bachillerato, ${ }^{8}$ quando na realidade tratam-se de sujeitos leitores cujo uso de textos escritos é instrumental e/ou informativo (dispostos em transportes, letreiros, avisos etc.), e cujo gosto por textos mais longos encontra-se associado a produtos culturais como revistas, historietas, livros temáticos (de moda, esportes, astrologia, tratados de psicologia, sociologia, economia).

Já no México, América Latina e em alguns países da África e Ásia, segundo a autora, a população considerada "analfabeta" geralmente é composta de pessoas que não leem e não escrevem porque não aprenderam a fazê-lo na infância, de pessoas que leem e escrevem pouco e com dificuldade, e também daquelas que leem e escrevem textos não reconhecidos como legítimos (Hernandes Zamora, 2004 apud Kalman, 2005, p. 14). Não é possível uma "visão aristotélica" de alfabetização, pois há duas dimensóes a se considerar, a social e a individual (Meek, 1991 apud Kalman, 1996a, p. 40):

[...] por un lado, la alfabetización se construye socialmente y se utiliza en el contexto de las relaciones sociales, pero, por otro lado, son individuos los que aprenden a leer y a escribir y a emplear la lectura y la escritura (Kalman, 1996a, p. 40).

A autora esclarece que mesmo nos usos íntimos, a leitura e a escrita da "própria palavra" têm origem no espaço público e são, portanto, sociais, uma vez que o que ocorre no plano individual deve ocorrer antes no social (Kalman, 2005). Tal perspectiva

8. Período de três anos, também conhecido no México como preparatória, que antecede o ingresso na universidade. No Brasil, equivale ao ensino médio. 
coaduna-se à teoria sociocultural, para a qual uma das premissas é entender o pensamento e o conhecimento tanto individuais como sociais, na medida em que são produto da apropriação ${ }^{9}$ de formas discursivas e de experiências compartidas (Kalman, 2005, p. 12). Judith Kalman convida-nos a mirar a pluralidade do fenômeno - alfabetizaçóes - compreendendo leitura e escrita como práticas sociais, como recursos comunicativos com usos autênticos, em contextos de aprendizagem em que a interaçáo entre sujeitos é extremamente significativa e recursivamente relacionada ao acesso, disponibilidade e apropriação na produção de bens culturais, incursos numa cultura escrita.

Importante destacar que os estudos de Kalman estão inscritos na perspectiva dos Nuevos Estudios sobre La Lengua Escrita (Street, 1993 apud Kalman, 1999-2000), que enfatiza a construção do objeto de estudo a partir de seu contexto de uso:

En 1993, Street usó la frase "nuevos estudios sobre la lengua escrita” para nombrar aquellos estudios sobre la alfabetización (entendida como un fenómeno social e individual), que buscan pintar un retrato fino de los múltiples usos de la lengua escrita; ubicar a ésta en relación con las prácticas comunicativas de la lengua oral; presentar la complejidad de significados de la lectura y escritura, y descubrir su lugar en la vida comunicativa de las personas y de sus comunidades. En esta línea de trabajo, los investigadores se preguntan cuál es la organización social de la lectura y de la escritura y cómo se vincula con las relaciones de poder en distintos contextos sociales, políticos, económicos, culturales y religiosos.

9. Kalman adota o conceito de apropriação de Bakhtin (Hicks, 1996, p. 107 apud Kalman, 2005, p. 12): "[...] Cuando los hablantes-pensantes individuales participan en las actividades que involucran los discursos de su cultura, forman también una respuesta dialógica a estos discursos. [...] La apropiación engendra una forma dialógica de la consciencia... el individuo construye nuevas formas de respuesta al mismo tiempo que se apropia de los discursos del mundo social”. 
Sendo assim, a autora em suas pesquisas utiliza-se frequentemente do conceito de cultura escrita - que alude simultaneamente a dois fenômenos, claramente distinguíveis, mas intimamente vinculados (Kalman, 1999-2000):

[cultura escrita] Por un lado, se refiere a la cultura que se escribe: desde las grandes obras literarias y los tratados científicos donde se resguardan la experiencia humana y su conocimiento acumulado, hasta los textos legales y administrativos que cristalizan las relaciones sociales y políticas y, por lo mismo, sirven de doctrina para gobernar la vida en sociedad. Incluye también los usos fugaces de la escritura: los mensajes, las listas, las notas, los letreros, los avisos, entre otros. Por otro lado, cultura escrita alude a la cultura que surge al usar la escritura; las prácticas, usos y convenciones de la palabra escrita y cómo estas se enraízan en contextos específicos, relaciones de poder y la vida comunicativa de las personas. En este sentido, la noción de cultura escrita agrupa tanto a los textos como sus dimensiones históricas, sus contextos de uso, sus formas, sus interpretaciones y, sobre todo, la ubicación de la escritura en cuanto uso de lenguaje en un tejido social.

Quando usa especificamente o termo alfabetização, Kalman (1999-2000) sempre se refere à leitura e à escrita como "práticas comunicativas situadas", nas quais o significado cobra sentido em "contextos de uso". O contexto ${ }^{10}$ de uso, para a autora, é uma construção dinâmica, negociada e forjada pela participação dos diferentes atores em um evento comunicativo.

A noção de práticas de língua escrita desenvolvida pela autora (Kalman, 1999-2000) abarca: a) participação em eventos comunicativos nos quais se lê e se escreve (ou se fala de leitura e de es-

10. A partir da leitura de Gumperz, a autora concebe contexto como a intercessão entre dinâmica da interaçáo e os processos sociais, históricos, econômicos, culturais relevantes; afinal, as ações comunicativas não se dão no vazio de significados socioculturais (Gumperz, 1984, 1986 apud Kalman, 2004, p. 9). 
crita); b) convençóes e formas particulares de uso; e c) ideias dos participantes sobre si mesmos enquanto leitores e escritores e o que pensam acerca das práticas da língua escrita (leitura e escrita, suas formas, convençóes e usos).

Nesse sentido, a noção de prática combina tanto açóes de ler e escrever como o que os diferentes atores pensam e expressam sobre essas ações (Hymes, 1986; Heath, 1983 e Street, 1993 apud Kalman, 1999-2000). Em concordância com a perspectiva teórica de Dyson (1997) e Heath (1983), Kalman (2004) desenvolve o conceito de alfabetização como algo mais do que a aprendizagem de aspectos rudimentares da leitura e da escrita. Ser alfabetizado, em sua perspectiva, é saber utilizar a língua escrita para participar do mundo social; é saber manipular a língua escrita — as palavras, os gêneros textuais, os significados, os discursos, as letras, de maneira intencional, para participar de eventos culturalmente valorizados e relacionar-se com os outros (Kalman, 2004, p. 8).

A visão social da alfabetização de Judith Kalman (1999), portanto, se sustenta em quatro pilares: a) alfabetização como prática social; b) noção de alfabetizaçóes múltiplas; c) relação entre contexto de aquisição e práticas adquiridas; d) restituição dos usos cotidianos da língua escrita.

A autora considera ainda muito limitado nosso conhecimento sobre como adultos de baixa ou nula escolaridade utilizam a língua escrita. Em busca de contextos de usos, Kalman (1999-2000) procurou observar práticas comunicativas com o uso da língua escrita entre mulheres com este perfil no México, e pôde identificar que, mediante a abordagem no contexto social, mulheres trabalhadoras, ainda que com baixa escolaridade, entendiam/ compreendiam/interpretavam textos que circulavam socialmente em suas vidas cotidianas. A partir do estudo de categorias analíticas de uma "carta de recomendação" e das concepçóes daquelas mulheres a respeito desse gênero, Kalman afirma que estas 
demonstravam conhecimento sobre as práticas sociais da língua escrita bem como os propósitos e as consequências dos usos da leitura e da escrita em diferentes cenários da vida cotidiana e do mundo social. A autora reforça que a escrita, para essas mulheres, significava compromisso. Nesse sentido, náo deixavam de se ver como escritoras, ainda que potencialmente de um tipo específico de documento como, por exemplo, a carta de recomendação. Tal constatação contradiz as afirmaçóes mais frequentes da literatura sobre o tema de que as pessoas de baixa ou nenhuma escolaridade se sentem impotentes e excluídas do mundo social por não lerem nem escreverem bem (Lind Johnson, 1990 apud Kalman, 19992000). Ao contrário, o estudo da autora permite supor que essas pessoas se concebem como participantes do mundo escrito por escolherem como e quando participar.

Contudo, não é possível desvencilhar a questão da alfabetizaçâo da questáo do poder. Kalman (2004) afirma que alfabetizar-se, longe de ser apenas uma questão de vontade individual, requer oportunidades socialmente construídas para aprender a ler e escrever, e que estas estáo imersas em relaçôes de poder, seja no posicionamento de poder sobre quem lê e escreve; sobre quem decide as convençóes normativas e exerce poder por meio da língua escrita. Chartier (1997 apud Kalman, 2004) considera que a distribuição desigual da língua escrita é mais bem compreendida pelo estudo das modalidades de apropriação, das práticas de interpretação e da relação entre as formas de representação e as práticas de leitura e escrita.

Diante do advento das novas tecnologias da informática e comunicação, Kalman (2013) também se interessou sobre as transformaçóes nas práticas de leitura e escrita nesse contexto, compreendendo a alfabetização enquanto apropriação de múltiplas e diversas formas de participação social mediadas por textos escritos (impressos, manuscritos ou eletrônicos). A autora considera 
que as práticas de leitura e escrita que temos hoje são resultado de seu uso e evolução ao longo do tempo: “[...] a língua escrita é uma opção cultural, composta por variadas práticas comunicativas, formatos, significados e usos da leitura e da escrita; e é também portadora de infinitos conteúdos, ideias e mensagens socialmente constituídos e historicamente desenvolvidos" (Kalman, 2000, p. 248).

Para a autora, a alfabetização visa ao uso competente da língua escrita para saber operar e atuar no mundo social e se adaptar, podendo lançar mão das novas tecnologias da comunicação que surgem no decorrer do processo histórico, e que não estão dispostas a todos os grupos e sociedades de forma igualitária. Assim, a alfabetização é concebida como capaz de proporcionar o uso potencializador das tecnologias de acordo com seu lugar de origem e, também, de instrumentalizar cada sujeito na busca de sua emancipação em uma sociedade grafocêntrica e tecnológica.

Judith Kalman (1996b) sugere, ao alfabetizador, “imaginação pedagógica”, para usar seu conhecimento sobre a língua escrita em prol da incorporaçáo da leitura e escrita no repertório comunicativo dos participantes do seu círculo, ampliando o conceito de alfabetização. A “imaginação pedagógica” tem a ver com a capacidade de o educador responder com criatividade e inteligência ao desafio de desenvolver uma visão integral das práticas de leitura e escrita junto aos educandos, envolvendo-os em seus próprios processos de aprendizagem, que devem ser pautados em interesses comuns e ações de colaboração e solidariedade.

Soares (2004) defende a interdependência e indissociabilidade dos conceitos de alfabetização e letramento, mas também a especificidade destes, alegando que a fusão dos dois processos acabou por gerar certa prevalência do letramento em detrimento da alfabetização. Para a autora, é conveniente a conservação dos dois termos, como processos de natureza fundamentalmente diferentes, 
envolvendo conhecimentos, habilidades e conhecimentos específicos, que implicam aprendizagens diferenciadas e consequentemente procedimentos diferenciados de ensino. Soares (2004, p. 14, grifo nosso) define alfabetização como aprendizagem das relaçóes grafofônicas (grafema e fonema), como parte integrante do processo de aquisição da língua escrita: "[...] a alfabetizaçáo desenvolve-se no contexto de e por meio de práticas sociais de leitura e de escrita, isto é, através de atividades de letramento, e este, por sua vez, só se pode desenvolver no contexto da e por meio da aprendizagem das relaçóes fonema-grafema, isto é, em dependência da alfabetização". Soares (1985), ainda no curso dos anos 1980, já chamava a atenção para a necessária articulação e integração de estudos e pesquisas a respeito das diferentes facetas da alfabetização: psicológica, psicolinguística, sociolinguística e linguística. Apontava a aprendizagem pretendida nas escolas como despida de caráter político, pautadas em uma visão de déficit linguístico e cultural, uma vez que as práticas linguísticas das crianças de classes populares não eram valorizadas e aceitas. No seu entender, tal preconceito linguístico afetava o processo de alfabetização, levando ao fracasso escolar.

Esteban (2012) chama a atenção para o fato de, no Brasil, exames de avaliação de alfabetizaçáo de larga escala integrados a políticas públicas, desde 2008 (Provinha Brasil), corroborarem a simplificação do conceito de alfabetização como aquisição de convençóes do código escrito. Para a autora, a natureza do programa aplicado no ensino fundamental regular é altamente regulatória, seus resultados interferem nos fazeres da escola, limitam a autonomia pedagógica, além de desconsiderar subjetividades e diversidades.

Cook-Gumperz (2008, p. 32) afirma que a forma com que "[...] enxergamos as consequências ou os efeitos da alfabetização está essencialmente relacionada com a nossa definiçấo ou avalia- 
ção da atividade em si”. Esteban (2012) destaca a necessidade de se considerarem as dimensóes cultural, social e política da alfabetização no processo avaliativo. A prática alfabetizadora, em seu entender, deve articular a leitura da palavra e a leitura de mundo, como definiu Paulo Freire, náo considerando a alfabetização um mero domínio do código escrito. A alfabetização para Esteban (2012) é parte das relaçóes socioculturais em que múltiplos textos se configuram e nas quais os sujeitos dialogam com seus sentidos, sendo a escrita uma prática intersubjetiva. Por ser um processo complexo, com implicaçóes sociais, culturais e políticas, a alfabetização não se dá de uma forma única, nem ao mesmo tempo a todos. "Participar, ainda que numa posição marginal, da cultura escrita faz da criança [do adulto] muito mais do que mera aprendiz de uma técnica de codificação e decodificação de mensagens" (Esteban, 2012, p. 582).

\section{Trançando concepçóes e achados: algumas sínteses}

Os autores selecionados deixaram entrever concepçóes em disputa, definiçóes em constantes mudanças. Há tanto aproximaçóes como afastamentos entre os conceitos de alfabetização e letramento - ora vistos como equivalentes, ora considerados distintos - assim como a presença do termo cultura escrita em estudos mais recentes sobre a aquisição da língua escrita.

Nos anos 1970, o conhecimento disponível sobre processos de alfabetização seguramente náo contribuía para que se pensassem programas de alfabetização com a riqueza de compreensóes como as trazidas ao texto pelos autores estudados. Mas Paulo Freire já representava, nas experiências que realizou, um olhar mais distante do que significava ensinar a ler e a escrever a jovens e a adultos. Não era seu "método de alfabetização", como se referem alguns, o que realmente inovava e importava. Era sim a concepção 
de homem inacabado, pleno de experiências e modos de conceber e conhecer o mundo que, em interaçáo, aprende mais do que é ensinado; sem ponto de chegada, porque o aprender se faz por toda a vida.

A centralidade do sujeito humano nos processos de aprendizados flexionava irremediavelmente os modos como se concebiam práticas escolares - prenhes de técnicas e procedimentos de ensino que, supostamente, faziam aprender a qualquer sujeito, sem levar em conta suas especificidades, singularidades, experiências de classe, de gênero, de cor/raça. Se os chamados "métodos de alfabetização" serviam para ensinar a ler e a escrever, não eram exatamente eles que o conseguiam: era a açáo dos sujeitos sobre o mundo, sobre o novo objeto de conhecimento - as culturas escritas - que se dispunham a esses sujeitos, acionadas suas memórias, histórias, experiências com e pela produção de sentidos, atribuídos a qualquer objeto de conhecimento, pela curiosidade humana em busca de compreensão/explicação do mundo. Por isso, na atualidade, o lugar de Freire está garantido pela dignidade recuperada aos sujeitos náo alfabetizados, como sujeitos de pensamento e ação, que careciam, em uma sociedade tão desigual quanto a nossa na metade do século passado, do reconhecimento como seres humanos de conhecimento, desejos e vontades, que a sociedade capitalista invisibiliza(va) com o arsenal de lógicas movido para "naturalizar" a desigualdade e justificar a opressão sobre os despossuídos de bens materiais. Paulo Freire não inovou pelo método de alfabetização, mas pelos princípios por quais restituiu a centralidade do sujeito - e suas experiências, contexto e singularidades - nos processos de aprendizado.

O método de alfabetização usado pelas Fundaçôes restringia-se, como se pode observar, ao que estava disponível naquele tempo histórico: palavras que, escandidas em sílabas, formavam novas palavras, porque a técnica resolvia o "problema" dos não 
alfabetizados. Materiais didáticos de diferentes editoras atestam a concepção corrente, com pouquíssimas variações. Paulo Freire, interditado como teórico que fez da experiência de Angicos um marco histórico, não podia ser evocado no contexto da ditadura civil-militar que criara o Mobral. O que os documentos e os materiais não deixam ver, entretanto, é que pessoas que pensavam a educação de adultos para um país desigual, com dados alarmantes de não acesso à educação, à cultura e à vida digna, poderiam fazer, no cotidiano, subversóes nas práticas de ensinar e aprender, mesmo que em maioria os alfabetizadores fossem leigos e carecessem, eles também, de formação e escolarização.

O limite da pesquisa, entretanto, não chegou a esses alfabetizadores - que certamente ainda estão pelo país e têm muitas histórias para contar —, mas, em algumas iniciativas de investigação realizadas com alfabetizandos, a ação alfabetizadora, por eles narrada, não deixa dúvidas de que, para muitos, foram as campanhas do Mobral as únicas oportunidades que chegaram aos territórios em que viviam, e que abraçaram com a tenacidade dos que sabem o valor e o poder de saber ler e escrever na sociedade.

Se do ponto de vista dos documentos institucionais e internacionais as concepçóes se afinavam, a história não deu a isso valor, porque a ideologia reinante alimentava o imaginário social de rejeição à instituição, apontada como serviçal do regime. A visáo de instituição monolítica, de pensamento único jamais deixou de perceber as existentes e reais contradiçôes forjadas em seu interior e nas práticas realizadas, porque diálogos entre contextos politicos (de texto) e contextos da prática não foram acionados em relação à compreensão do que significou, à luz da pesquisa histórica, uma instituição de vinte anos de atuação tão diversa, em campos tão vastos além da educação, como a cultura, a saúde, o trabalho etc., para além dos (pre)conceitos que carregou e ainda carrega. Retirar essa instituição — e sua sucedânea, a Educar — das sombras da 
caverna em que se mantém isolada na história da educação brasileira é libertar a memória de um tempo... independentemente de sua origem, ideologia, contextos em que foi produzida e atuou. A tarefa de pesquisadores não se limita aos temas-problemas que não causam desconfortos à sua trajetória: implica tratar, com as lentes do saber científico e dos conhecimentos que atualizam e oferecem ferramentas sobre o produzir de pesquisas, de quaisquer temas, oferecendo à compreensão da sociedade melhores conhecimentos sobre o vivido, assegurando a preservação do passado e do que nos forjou, como sujeitos do presente.

As entrevistas realizadas também oferecem outras variaçóes capazes de contribuir na compreensão dessa perspectiva para além de uma única visada da história. Apesar do interesse em mais duas entrevistas, como mais duas vozes sobre concepçóes de alfabetização no tempo focalizado, muitos obstáculos se interpuseram para que pudessem se realizar, alguns ligados às pretensas entrevistadas e outros referentes às condiçóes vivenciadas por nós, pesquisadores, institucionalmente.

A primeira entrevistada, nomeada A (mantendo o anonimato), ${ }^{11}$ teve ativa participação na Fundação Mobral, mas não na Fundação Educar. Além de outras funções, dirigiu a gerência pedagógica, de cujo lugar deu direção política e pedagógica a programas de alfabetizaçáo, ${ }^{12}$ de educação integrada, ${ }^{13}$ de autodidatismo e de formação de alfabetizadores. Como acontece nas funções públicas, mudanças na presidência do órgão a afastaram,

11. Embora cargos e funçôes públicas prescindam de anonimato, optamos por preservar as identidades no corpo da pesquisa, o que em nada prejudica os depoimentos, nem as contribuiçóes da memória desses atores sociais.

12. Programa de Alfabetização Funcional (PAF).

13. Programa de Educação Integrada (PEI), correspondente às quatro primeiras séries da antiga escola primária, oferecido em sequência, em parceria com as redes públicas, para absorver as pessoas alfabetizadas, dando continuidade à escolarização, com a convicção de que, se tal não ocorresse, a pessoa poderia regredir em seu processo de aprendizado da língua escrita. 
indo trabalhar em outra instituição federal ligada a projetos educativos, mas não especificamente de educação de adultos nem de alfabetização. A instituição produzia programas educativos de televisão, e nela permaneceu por muito tempo, até aposentar-se.

A segunda depoente, nomeada $B$, iniciou sua trajetória em uma coordenaçáo estadual do Nordeste — órgão descentralizado e executor homólogo do central —, em que ocupou o cargo de agente cultural e de agente pedagógica, lidando diretamente com programas de cultura e, em seguida, de alfabetização e sua continuidade. Mais tarde, veio para o Rio de Janeiro frequentar um curso de especialização em educação popular e de adultos promovido pelo Mobral em convênio com a Universidade Santa Úrsula. Pouco depois da conclusáo, voltou ao Rio e passou a atuar no órgão central. Na Fundação Educar, sucedânea do Mobral no tempo da Nova República, pós-ditadura militar, participou da equipe que desenvolveu o programa de televisão Verso e Reverso - Educando o educador, realizado em convênio com a TV Manchete, em três séries ${ }^{14}$ de 24 programas voltados a alfabetizadores.

Percebemos, logo na primeira entrevista, o inusitado diante de nós. Havia o receio de que a depoente fosse se comportar de maneira reticente, até mesmo pelo ambiente que escolheu para sua ocorrência - seu local de trabalho - e a prévia delimitação do horário concedido para o encontro, no entanto, ao perceber que estávamos abertos e tentando náo trazer concepçóes prévias sobre a instituição e o trabalho por ela desenvolvido, mostrou-se sur-

14. Verso e Reverso era um projeto que incluía três modalidades de formação de alfabetizadores, ofertadas isoladamente ou associadas, valendo-se do uso de tecnologias. A primeira, mais relevante e cara, era a televisão; a segunda, o material impresso em módulos, desenvolvido em um curso por correspondência; e a terceira, o rádio. Os módulos só tiveram uma versão impressa, TV e rádio três séries, mas a terceira não chegou a ser concluída, nem pela TV nem pelo rádio, ficando pela metade (treze programas, pois havia dois de orientaçấo quanto ao uso dos programas via TV e rádio), pela extinção da Fundação Educar em 1990, tão logo assumiu o primeiro presidente eleito diretamente, pós-ditadura militar, Fernando Collor de Mello. 
presa e colaborativa. Suas narrativas trouxeram revelaçóes que causaram certa polêmica no GP e desafiaram a pesquisa a entender melhor concepçóes e práticas que se desenvolveram nos processos de alfabetização e de escolarização de jovens e adultos nas décadas de 1970 e 1980, em um órgão sempre nomeado como aparelhado pela ditadura civil-militar, incapaz de possibilitar contradiçóes, modos de pensar divergentes e autonomia profissional dos técnicos.

No tratamento inicial do material produzido nos encontros dialógicos, não só a comunicação verbal, mas também a não verbal - expressóes corporais, emoções manifestas durante os relatos, entonação das falas e mesmo os silêncios - tornaram-se objetos de observação e reflexão. Assim, não passou despercebida a emoção que atingiu as duas entrevistadas quando perguntadas sobre o que representara o trabalho no Mobral em suas vidas. A emoção aflorou, os olhos se encheram de lágrimas e ambas se referiram a um tempo extremamente fértil em ideias, em liberdade para fazer e criar, em descortinar um mundo para além das formaçóes primeiras com que ambas chegaram à Fundação.

As duas depoentes foram unânimes em afirmar o que significou o trabalho profissional na(s) Fundação(óes): "uma escola", repetem, com emoção. Dizem que ali aprenderam a trabalhar; que se formaram como profissionais; que tiveram oportunidade de interagir com diferentes intelectuais reconhecidos no campo, à época, tanto em nível nacional quanto internacional. Que os aprendizados dessa "escola" lhes serviram para todas as demais funçóes que exerceram na vida, depois que de lá saíram (A em 1985; B em 1990).

Bourdieu (1983, p. 124), ao legitimar o intelectual no campo científico, afirma que um sujeito é marcado pelas instituiçóes a que pertenceu, e que "[...] os julgamentos sobre a capacidade científica de um estudante ou de um pesquisador estáo sempre 
contaminados, no transcurso de sua carreira, pelo conhecimento da posição que ele ocupa nas hierarquias instituídas”. Transpusemos essa compreensão do sociólogo aos entrevistados e isso fortaleceu o pensamento de que ao resgatar memórias dos que estiveram ligados a essas instituiçóes, atuando na formulação, implantação, acompanhamento e avaliação de programas de alfabetização, de formaçáo de alfabetizadores ou outros correlacionados, muito se revelava das concepçóes que guiaram as açóes planejadas e executadas por essas entidades.

Sobre concepçóes de alfabetização, ambas afirmaram que o trabalho desenvolvido tinha fundamento no conhecimento existente na época, e que o acesso à produção, a autores e pesquisadores era irrestrito. Isso incluía o curso de especializaçáo em educação popular já mencionado, oferecido pela própria instituição, a técnicos de todo o país que se deslocaram para o Rio de Janeiro, com apoio da instituição, para realizá-lo, após um processo de seleção. Também informam a íntima conexão que a instituição tinha com organismos internacionais como a Oficina Regional de Educación para América Latina y el Caribe (OREALC), com sede no Chile, contribuindo em eventos organizados para os quais era instituição convidada e assumindo materiais e publicaçóes de acordos internacionais de que também participava. Vários técnicos faziam cursos de mestrado e doutorado em universidades, desfrutando de tempos em seus trabalhos para cursarem disciplinas requeridas.

\section{Consideraçóes finais}

Nossa pesquisa finalizou-se e o lançamento do site do CReMEJA consagrou a disponibilização dos materiais do acervo. Muitos aspectos podem ser destacados de todo esse vasto movimento de compreensão da alfabetização nas décadas de 1970-1990. Pode-se 
começar indicando o quanto fatores relacionados ao modo como se investiga em grupos de pesquisa na pós-graduação em educação afeta e altera o fazer individual, para trançar, em rede, pesquisadores experientes e outros em formação. Participando, como processo de formação, estudantes de mestrado, de doutorado e bolsistas de iniciação científica, além de outros profissionais interessados na pesquisa acolhidos de modo igual nesses grupos, favorecem o desenvolvimento do projeto e, especialmente, possibilitam metas mais arrojadas e complexas de abordagem da realidade. Permitem o exercício do coletivo e a experiência de investigação conjunta, quando cada participante pode dispensar ao projeto o que de mais relevante pode aportar à construçáo do objeto de estudo, às compreensóes e teorizaçóes que se façam sobre ele, assim como ao delineamento que melhor aproxime as abordagens metodológicas definidas à realidade investigada.

Trabalhar em grupo de pesquisa faz com que cada sujeito aprenda a compartilhar saberes, conhecimentos e achados, reduzindo a competição entre pares e ampliando a cooperação/colaboraçáo. Nesse processo, também o coordenador e responsável pela pesquisa exercita processos de formaçáo de novos pesquisadores e aperfeiçoa seus modos de investigação, pelo rico diálogo que mantém com a diversidade de percepçóes, acuidades sobre os fenômenos e sobre a natureza de pessoas plurais e múltiplas, que forjam e (re)formam cotidianamente uns aos outros. Esse aspecto não apenas interfere positivamente na pesquisa do coordenador, mas, excepcionalmente, na de cada estudante em formaçáo, no âmbito de suas próprias pesquisas de mestrado, doutorado e/ou de IC. Então relevo positivamente a qualidade das investigaçóes que se vinculam ao projeto-mãe, nem todas exatamente desdobradas dele, mas que guardam relaçóes e vínculos fortes pelas abordagens epistemológicas e teóricas, assim como pelos modos de produzir um pensamento mais complexo sobre a realidade investigada. 
Ainda cabe destacar o quanto o financiamento em pesquisas significa para a produção de conhecimento, náo apenas de quem a propóe ou a coordena, mas de toda uma equipe que, conjuntamente, pode avançar na experiência de investigação. A proximidade com campos empíricos, com obras, com outros pesquisadores em eventos e em atividades realizadas favorece muito o processo do pesquisar, razão pela qual todo financiamento pode se multiplicar porque beneficiando a muitos, e não apenas a quem faz a coordenação da investigação.

No que diz respeito especificamente ao objeto investigado, pode-se afirmar que a marca ideológica pela qual a memória das instituiçôes foi tratada parece ser a melhor explicação que ajuda a compreender o descaso com uma produção resultante de açóes voltadas à educação de adultos por vinte anos. $\mathrm{O}$ desprezo com a memória das instituiçóes - e, consequentemente, com a história que essa memória encerra - é um traço flagrante nesse caso, e só o esforço de pesquisadores isolados é insuficiente para resgatar um patrimônio que, em mais alguns anos, estará inteiramente perdido, sobre o qual o campo de formação da educação nem mais se lembrará, caso não seja recuperado com o valor que açóes de preservação devem a ele creditar.

Diferentemente das experiências de educação popular, pouco ou nada se escreveu, nem se pesquisou sobre a ação dessas Fundaçóes que, a despeito do momento histórico que as criou e manteve, foram poderosas organizaçóes educativas existentes e atuantes no país, responsáveis em larga escala por açóes abrangentes de alfabetização e outras atividades, principalmente no campo da cultura, atingindo todos os municípios brasileiros, e com recursos próprios. Pode-se assegurar que em nenhum outro momento se teve um sistema de educação de adultos de tal envergadura, e que as demais açóes, desde a extinção, pouco avançaram em concepçóes em relação a esse tempo, e menos ainda em abrangência, estruturação e alcance. 
A crítica que se faça ao modus operandi dessas instituiçóes não pode negá-las, mas deve pôr à luz o que produziram, atentos à possibilidade de contradiçóes que a existência de pessoas qualificadas e comprometidas com a finalidade institucional permitiram acontecer, invertendo a lógica de que um pensamento monolítico as dominava. Não cabe mais rejeitá-las, como se fosse possível continuar interditando a pesquisa para manter a hegemonia de um modo ideologizado de compreendê-las que prevaleceu intacto, mesmo após 27 anos da extinção. Dobrar os desejos de coraçóes e mentes que atuaram em prol da educaçáo de adultos, sem deixar emergir o que foram capazes de produzir, em um país que ainda hoje sofre com a desigualdade educacional e tenta assegurar o direito à educação para todos, desde que foi reconhecido pela Constituição Federal de 1988, não se sustenta sob o Estado democrático de direito, para o qual a história ocultada só corrobora os ataques permanentes feitos às lutas pela igualdade.

Por essas razóes, que se explicitaram cada dia mais no desenvolvimento da pesquisa, especialmente a partir de olhares de fora - os pesquisadores jovens em formaçáo - , que nem viveram aquele tempo, nem compartilharam a memória, e que apenas foram levados a convicçóes preestabelecidas pelas narrativas hegemônicas sobre o significado das duas Fundaçóes, compreendemos a relevância do estudo realizado, ainda que seja ele uma pequena parte de um conjunto muito mais amplo, que se póe à disposição de outros pesquisadores e exigirá muitas açóes que os priorizem como objetos. Mantida a pesquisa em íntima relação com o projeto do CReMEJA, síntese do zelo com a memória que muitos pesquisadores do país abraçaram como projeto e compromisso de vida, e em diálogo com outras universidades e pares, tem-se conseguido reunir e sistematizar um acervo que, sem dúvida, será mantido com os recursos da tecnologia para as próximas geraçóes, impedindo a dispersáo e o apagamento da memória 
da educação de adultos no país, ainda que parcialmente. $\mathrm{O}$ projeto fez-se como um primeiro estudo sobre parte da memória do acervo, trazendo à luz contribuiçóes e aprendizados quanto a concepçóes de alfabetização vigentes em um tempo histórico e que, ao que parece, guardam muita atualidade em relação ao que sabemos e conhecemos na contemporaneidade.

A síntese que os resultados apresentam pode ser assim resumida:

a) apesar de todas as imputaçóes às instituiçóes, especialmente à primeira (Mobral), cuja atuação decorre durante a ditadura civil-militar, observou-se que havia espaço para ideias e propostas náo alinhadas a um possível e suposto pensamento hegemônico: ou seja, jamais as contradiçóes puderam ser apagadas mesmo em contextos de repressão e controle de exceção e de liberdades individuais;

b) a alfabetização e suas concepçóes - expressas nos projetos e programas —, tal como vista pelos organismos internacionais, apresentavam um tom de neutralidade, e assumiam o lugar de "passo inevitável" para o desenvolvimentismo industrial aberto às multi e transnacionais que se implantavam com a ditadura civil-militar. Exigência para que maior produtividade fosse esperada da máo de obra em larga escala demandada dessas indústrias nascentes. Essas concepçóes ainda persistem na atualidade, convivendo em tensão com abordagens que têm pouco espaço nas políticas públicas e nas práticas pedagógicas, mesmo quando os professores têm formação de nível superior;

c) as análises da alfabetização de um tempo histórico não podem ser vistas sem o efeito que causam/causaram nos sujeitos que os vivenciaram, fossem alfabetizandos, técnicos ou educadores. Exigem a compreensão na rede de 
relaçóes - os contextos de uso - que as produziu, movendo pensamentos complexos, não lineares. As memórias desses sujeitos evidenciam inusitadamente mais positividades do que as críticas que lhes possam ser dispensadas por acadêmicos, quase todas insuspeitadas.

Por fim, o artigo demonstra o quanto um projeto desenvolvido de forma coletiva é fértil de ideias em todos que compartilham seu fazer. Mais do que seus resultados, a riqueza dos processos vivenciados e seus aprendizados ilustram a complexidade do fazer pesquisa em educaçáo, de modo cooperativo. Não se desprezem, entretanto, as produçóes do GP, que atestam a profícua criação e inventividade de temas e problemas que permeiam a pesquisa em educação de jovens e adultos e em alfabetização — em sentido lato, porque gênese de toda a criação que constitui a cultura escrita.

\section{Referências}

ALBERTI, Verena. Manual de história oral. 3 ed. Rio de Janeiro: FGV, 2005. BECKER, Jean-Jacques. "O handicap do a posteriori". In AMADO, Janaína e FERREIRA, Marieta de Moraes (orgs.). Usos e abusos da História Oral. Rio de Janeiro: FGV, 2006, pp. 27-31.

BENJAMIN, Walter. Rua de mão única. Trad. Rubens Rodrigues Torres Filho e José Carlos Martins Barbosa. 6 ed. rev. São Paulo: Brasiliense, 2012. (Obras escolhidas; v. 2).

BOURDIEU, Pierre. Questóes de sociologia. Rio de Janeiro: Marco Zero, 1983.

BOWE, R. et al. Reformig education and changing schools. Londres e Nova Iorque: Routledge, 1992.

COOK-GUMPERZ, Jenny et al. "Alfabetização e escolarização: uma equação imutável?”. In: A construção social da alfabetização. Ronaldo Cataldo Costa (trad.). Porto Alegre: Artmed, 2008, pp. 29-54 
ESTEBAN, Maria Tereza. "Considerações sobre a política de avaliação da alfabetização: pensando a partir do cotidiano escolar". Rev. Bras. Educ, vol. 17, n. 51, set./dez., pp. 573-92. Rio de Janeiro, 2012.

FERREIRA, Vitor Sérgio. "Artes e manhas da entrevista compreensiva”. Saúde e Sociedade, v. 23, n. 3, pp. 979-92, São Paulo, set. 2014. Disponível em: http://www.revistas.usp.br/sausoc/article/view/88581.

FREY, K. "Políticas públicas: um debate conceitual e reflexôes referentes à prática da análise de políticas públicas no Brasil". Planejamento e Políticas Públicas, n. 21, jun. 2000.

KALMAN, Judith e HERNÁNDEZ, Oscar. "Jugar a la escuela con pantalla y teclado". Revista Arquivos Analiticos de Políticas Educativas, v. 20, n. 73, Arizona State University, set. 2013.

. "Lecturas para la educación de adultos". Revista Mexicana de Investigación Educativa. Consejo Mexicano de Investigación Educativa. vol. 6, n. 11, México, jan./abr. 2001.

- "¿Somos lectores o no? Una revisión histórica del concepto de alfabetización y sus consecuencias". Novedades Educativas. Tomo 110, pp. 40-2, Argentina, 1996a.

- "Cultura Escrita: el aprendizaje de la lectura y la escritura para su uso em la vida cotidiana”. Decisio, pp. 3-9, 2003. Disponível em: http:// www.crefal.edu.mx/decisio/images/pdf/decisio_6/decisio6_saber1.pdf. Acesso em 6 de fev. 2016.

. "El estudio de la comunidad como un espacio para leer y escribir". Revista Brasileira de Educação, n. 26, pp. 5-28, Rio de Janeiro, 2004.

. "El origen social de la palabra propia". Lecturas sobre lecturas. Consejo Nacional para la Cultura y las Artes. v. 14, pp. 9-34, México, 2005.

- "La alfabetización desde una perspectiva social: los evangelistas en la Plaza de Santo Domingo". Encuentros de investigación educativa. n. 95-8, v. 2, pp. 55-77, México, 1999.

- "La imaginación pedagógica. El alfabetizador y el nuevo enfoque". Revista Interamericana de Educación de Adultos. v. 4, n. 1, pp. 9-23, México, 1996b.

- "Las prácticas de lectura y escritura frente a las nuevas tecnologías de comunicación e informática”. Encuentro Nacional y Encuentro de Investigación Educativa en el marco de la Feria Internacional del Libro. Guadalajara, 
México, nov. 2000.

KALMAN, Judith. "Ya sabe usted, es un papel muy importante: el conocimiento de la lengua escrita en mujeres de baja y nula escolaridad". Revista Colección Pedagógica Universitaria, n. 32-3, pp. 153-68, México, 1999-2000.

KAUFMANN, Jean-Claude. A entrevista compreensiva: um guia para pesquisa de campo. Petrópolis: Vozes; Maceió: Edufal, 2013.

LANG, Alice B. da S. G. "História oral: muitas dúvidas, poucas certezas e uma proposta”. In MEIHY, J.C.S.B. (org.). (Re)introduzindo história oral no Brasil. São Paulo: Xamá, 1996, pp. 33-47.

MOREIRA, Marco Antonio. Mapas conceituais e aprendizagem significativa. Porto Alegre, 2012. Disponível em: http://www.if.ufrgs.br/ -moreira/mapasport.pdf. Acesso em 5 fev. 2016.

NOLAN, Kathleen e TUPPER, Jennifer. “'Field' trips with Bourdieu: making sense as research methodology in teacher education". International Journal of Humanities and Social Science, v. 3 n. 6 [Edição especial - mar. 2013]. Disponível em: http://www.ijhssnet.com/journal/index/1688.

SGUISSARD, Valdemar. "Decifrando a história e o estigma do analfabetismo no Brasil". Educação \& Sociedade, v. 32, n. 114, pp. 245-9. Campinas, Brasil: Centro de Estudos Educação e Sociedade, jan.-mar. 2011.

SOARES, Magda. "Alfabetização e letramento: as muitas facetas". Revista Brasileira de Educação, n. 25, pp. 5-17, Rio de Janeiro, jan./abr. 2004.

. "As muitas facetas da alfabetização". Cadernos de Pesquisa, n. 52, pp. 19-24, São Paulo, fev. 1985.

SOUZA, Nadia Aparecida e BORUCHOVITCH, Evely. "Mapas Conceituais: estratégia de ensino/aprendizagem e ferramenta avaliativa". Educação em Revista. v. 26, n. 3, pp. 195-218. Belo Horizonte, dez. 2010.

TAVARES, Romero. "Construindo mapas conceituais". Ciências \& Cognição. vol. 12, pp. 72-85. Rio de Janeiro, dez. 2007.

THOMPSON, Paul. A voz do passado: História oral. Trad. Lólio Lourenço de Oliveira. Rio de Janeiro: Paz e Terra, 1992. 